\title{
National reference centiles of anthropometric indices and BMI cut-off values in a child
}

population in Nepal

Saujanya Karki ${ }^{1,2^{*}}$, Jari Päkkilä̈ ${ }^{3}$, Marja-Liisa Laitala ${ }^{1}$, Marja Ojaniemi ${ }^{4,5}$, Vuokko Anttonen ${ }^{1,2,5}$

${ }^{1}$ Research Unit of Oral Health Sciences, University of Oulu, Oulu, Finland

${ }^{2}$ Medical Research Center, University of Oulu, Oulu, Finland

${ }^{3}$ Department of Mathematical Sciences, University of Oulu, Oulu, Finland

${ }^{4}$ Department of Children and Adolescents, PEDEGO Research Center, University of Oulu, Oulu Finland

${ }^{5}$ Oulu University Hospital, Oulu, Finland

*Corresponding author

Email: Saujanya.karki@oulu.fi 


\section{Abstract}

Background: Need for national- or ethnicity-specific growth reference values is established in developing countries like Nepal where rapid urbanization and consequential nutritional transition is taking place.

Aims: To establish national growth reference percentiles for anthropometric indices, and to propose body mass index (BMI) cut-off values for Nepalese schoolchildren.

Methods: This study comprised 1135 Nepalese schoolchildren of four World Health Organization (WHO) indexed age groups (5-, 6-, 12-, and 15-year-olds). The age-and gender-specific smoothed percentile curves for anthropometric indices (height, weight, BMI, waist circumference, waist-tohip-ratio, and waist-to-height-ratio) were constructed using LMS method and the corresponding Zscores were computed. The Receiver Operating Characteristic analysis was used to determine BMI cut-off values based on the International Obesity Taskforce (IOTF) and the WHO growth references.

Results: The age- and gender-specified smoothed percentile values of anthropometric indices at 3rd, 10th, 25th, 50th, 75th, 90th, and 97th percentiles were computed. The BMI cut-off values for thinness (-1.2 SDS/12th percentile), overweight (+1.2 SDS/88th percentile), and obesity $(+2.1$ SDS/98th percentile), had high discriminating power, and high sensitivity and specificity.

Conclusion: The Nepali anthropometric cut off values proposed here can be recommended to be applied into research, and to identify public health risks in Nepal among these age groups.

Keywords: Adolescents, anthropometric, body mass index, children, Nepal. 


\section{Background}

Anthropometric indices are valuable in investigating long-term effects of nutrition on health among children and adolescents. The coexistence of both undernutrition and overweight/obesity among Asian children and adolescents has become one of the greatest global health challenges (AbarcaGómez et al., 2017). Additionally, the adverse consequences of being either under- or overweight or obese are associated with short- and long-term health impacts. According to the Nepal Demographic and Health Survey (2017), 36\% of children under the age of 5 years were stunted and $12 \%$ were severely stunted, even if the figures have improved in past two decades (Ministry of Health 2017). In contrast, the proportion of overweight and obese adolescent and adult Nepalese women (15-49-year-olds) has increased from 9\% in 2006 to 22\% in 2016 (Ministry of Health 2017). A school-based health survey reported that $11 \%$ of Nepalese adolescents are underweight and the proportion of the overweight and obese is $7 \%$ and 1\%, respectively (Aryal et al. 2017). Both surveys used the World Health Organization (WHO) based Z score reference values for determining underweight, overweight, and obesity. Genetic and environmental factors, timing of puberty, and nutritional differences influence the body composition mainly in children and adolescents and indicate a need for national growth reference values, the importance of which has been argued by many authors (Bonthuis et al. 2012; Natale and Rajagopalan 2014; de Wilde et al. 2015). Moreover, national- or ethnicity-specific growth reference values for children and adolescents are necessary in developing countries such as Nepal that are currently undergoing rapid urbanization (Muzzini and Aparicio 2013) and consequential nutritional transition (Subedi et al. 2017).

The first aim of this study was to establish age- and gender-specific growth reference percentiles for height, weight, body mass index (BMI), waist circumference (WaC), waist-to-hip ratio (WHR), 
and waist-to-height ratio (WHtR) for Nepalese schoolchildren. The second aim was to propose national BMI cut-offs for thinness, overweight, and obesity, evaluating their validity using the International Obesity Taskforce (IOTF) cut-offs for Asian populations (Cole and Lobstein 2012) and the WHO growth reference for 5-19-year-olds as golden standards- (World Health Organization 2007).

\section{Sample}

This school-based, clinical, cross-sectional study was conducted among four age groups (5-, 6-, 12-, and 15-year-olds) specified according to the WHO guidelines for conducting population-based oral health surveys (World Health Organization 2013). The study was carried out in 18 out of 75 districts in Nepal during April-July 2016. The districts were selected based on a stratified random sampling, and they represented the three ecological regions (Tarai, Hill, and Mountain) and the five administrative developmental regions (Eastern, Central, Western, Mid-Western, and FarWestern) of Nepal. After obtaining the list of schools from the Ministry of Education, a total of 27 schools (18 public schools +9 private schools, i.e. one to two schools per district) were selected conveniently. One school refused to participate, and consequently the total study participation response rate was $99 \%$.

The study protocol was approved by the Institutional Ethical Committee, Kathmandu University School of Medical Sciences (IRC No. 60/15, KUSMS) and the Northern Ostrobothnia Hospital District (18/2016). Written permissions were obtained from the Ministry of Health and the Ministry of Education, Government of Nepal, and the competent district health and education authorities also gave their permission for the study. A written consent was also obtained both from the school 
headmaster and from parents of the youngest children (5-6-year-olds), and a verbal consent was obtained from the children in the oldest age groups (12- and 15-year-olds).

\section{Data collection}

The anthropometric indices (height, weight, waist circumference, and hip circumference) were measured consecutively and recorded according to the WHO guidelines (WHO 1995; World Health Organization 2011). The height of the children was measured in centimetres with a portable stadiometer (Seca®, seca GmbH \& Co. KG, Hamburg, Germany) and weight was measured in kilograms using a self-zeroing portable electronic digital scale (Rossmax ${ }^{\circledR}$, Rossmax Swiss

GmbH, Berneck, Switzerland). The height and weight were measured after asking the children to stand upright with the back of the head, buttocks, and heels touching the stadiometer (without leaning backward or forward) and with only wearing a light school uniform (shirt, pants/skirt, and undergarments) but no head gear (cap, ribbon, or hairpins) or shoes. The waist circumference $(\mathrm{WaC})$ was measured at the midpoint between the lower ribs and the iliac crest $(\mathrm{cm})$, and hip circumference was measured around the widest portion of the buttocks $(\mathrm{cm})$. The waist and hip circumferences were measured after asking the children to stand with their arms wide open and feet positioned close together. All the measurements were done using an inelastic plastic measuring tape (Prym®, William Prym Holding GmbH, Stolberg, Germany) held snugly (without compressing the skin) at a level parallel to the floor.

The Body Mass Index (BMI) was calculated using the formula 'weight divided by the square of height' $\left(\mathrm{kg} / \mathrm{m}^{2}\right)$. The waist-to-hip ratio (WHR) was calculated as the waist circumference divided by the hip circumference. Similarly, the waist-to-height ratio (WHtR) was calculated as the waist circumference divided by the height. The five members of the survey team were trained to measure 
and record the anthropometric indices. The training sessions covered both theoretical and practical lessons before the field phase in April 2016.

\section{Data management and Statistical analysis}

The manually recorded data were transferred to electronic data and prepared for analyses. Descriptive statistics (frequencies, proportion, means, and standard deviation) and $95 \%$ confidence interval (95\% CI) were calculated for each anthropometric index (BMI, height, weight, WaC, WHR, and WHtR). Differences in the means between genders were analyzed using the independent samples t-test. A p-value $<0.05$ was considered statistically significant. The Statistical Package for Social Sciences (SPSS) software (IBM SPSS Statistics for Windows, version 24.0. Armonk, NY: IBM Corp.) and R version 3.4.3 (R Development Core Team, Vienna, Austria) were used in the analysis.

\section{LMS method}

The LMS method was developed by T. J. Cole in 1988 to adapt the growth standards by assuming their skewness to normal distribution after the Box-Cox power transformation (Cole 1990). The method also summarizes the change in distribution by three curves representing the skewness (L), median (M), and coefficient of variation (S). The age- and gender-specific smoothed percentile curves for BMI, height, weight, WaC, WHR, WHtR were separately constructed using the LMS method, computed using the LMS Chartmaker Light, version 2.54, software. A percentiles chart was constructed for each anthropometric index based on a pre-specified set of centiles (3rd, 10th, 25th, 50th, 75th, 90th, and 97th) on LMS software. Later, the corresponding Z scores were calculated for each anthropometric index using the previously obtained LMS values (Cole 1990). 


\section{ROC Analysis}

The Receiver Operating Characteristic (ROC) analysis was used to determine potential cut-off values for the anthropometric indices. The IOTF BMI cut-offs (Cole and Lobstein 2012) equivalent to BMI at the age 18 years (thinness grade 2 : BMI $<17 \mathrm{~kg} / \mathrm{m}^{2}$, overweight [unofficial Asian cutoffs]: BMI > 23-27 kg/m², and obesity [unofficial Asian cut-offs]: BMI > $27 \mathrm{~kg} / \mathrm{m}^{2}$ ) and the WHO growth reference (World Health Organization 2007) for 5-19-year-olds (underweight: <-2 SD , overweight: $>+1 \mathrm{SD}$, and obesity: $>+2 \mathrm{SD}$ ) were used as the gold standard for determining thinness/overweight/obesity. The discriminating power of the test variables was expressed as AUC with $95 \%$ confidence interval. The cut-off value for WHR as defined by the WHO (>0.90 for boys and $>0.85$ for girls) (World Health Organization 2011) and for WHtR (>0.5) as recommended by International Diabetes Federation (IDF) (Zimmet et al. 2007), were also taken into consideration when defining central obesity.

\section{Results}

The study population comprised a total of 1,135 children and adolescents. The mean age- and gender-specific anthropometric measurements of the study population, with standard deviation (SD) and 95\% confidence interval (CI), are presented in Table 1. The age- and gender-specified smoothed percentile values for the anthropometric indices are shown in Table 2.

The ROC analysis showed that the proposed Nepali national BMI had a high discriminating power to detect thinness, overweight, and obesity using the IOTF and WHO cut-offs as gold standards. The area under the curve (AUC) for thinness, overweight, and obesity was higher than 0.90 compared with both gold standards (Fig 1). For thinness, the BMI cut-off of -1.2 SDS had the maximum sensitivity and specificity (specificity of $99.5 \%$ and sensitivity of $86.2 \%$ using IOTF as 
gold standard and specificity of $98.2 \%$ and sensitivity of $73.9 \%$ with WHO criteria as gold standard). Similarly for overweight, the BMI cut-off of +1.2 SDS had the maximum sensitivity and specificity (IOTF: specificity of $96.6 \%$ and sensitivity of $100 \%$, and WHO: specificity of $93.4 \%$ and sensitivity of $100 \%$ ). For obesity, the BMI cut-off of +2.1 SDS had the maximum specificity and sensitivity (IOTF specificity of $99.1 \%$ and sensitivity of $100 \%$, and WHO specificity of $98.6 \%$ and sensitivity of $100 \%)$.

The IDF recommended WHtR reference ( $>0.50)$ used here also had a high discriminating power to detect central obesity, although the sensitivity compared with IOTF was $69.2 \%$, while the specificity was higher at 91.6\% (AUC 0.87; 95\% CI, 0.84-0.98) (Fig 1E). The respective figures WHO criteria as gold standard were specificity $91.3 \%$ and sensitivity of $71.4 \%$, and AUC 0.86 (95\% CI, 0.66-1.00) (Fig 1F). WaC cut-offs of +1.28 SDS or $>90$ th percentile (recommended by the WHO) to define obesity had specificity of $93.5 \%$ and sensitivity of only $46.7 \%$ (AUC 0.69 ; $95 \% \mathrm{CI}, 0.50-0.87$ ) when using IOTF as the gold standard, and specificity of $92.9 \%$ and sensitivity of only $60.0 \%$ (AUC $0.55 ; 95 \%$ CI, $0.32-0.78$ ) when using WHO as the gold standard. WHR proved to be a less reliable measure for detecting central obesity, as the cut-off of WHR $>0.90$ for boys and $>0.85$ for girls had specificity of $67.0 \%$ and sensitivity of only $53.8 \%$ (AUC 0.56 ; $95 \%$ CI, 0.42-0.71) when using IOTF as the gold standard, and specificity of $67.0 \%$ and sensitivity of only $71.4 \%$ (AUC $0.52 ; 95 \%$ CI, 0.34-0.69) when using WHO as the gold standard.

The proposed age- and gender-specific BMI cut-off values for thinness (-1.2 SDS/12th percentile), overweight (+1.2 SDS/88th percentile), and obesity (+2.1 SDS/98th percentile), obtained by ROC analysis, with their maximum sensitivity and specificity values are presented in Table 3 . As an example, the Nepali BMI cut-off points for 15 -year-old boys are: BMI $<16.39 \mathrm{~kg} / \mathrm{m}^{2}$ for thinness, 
$>21.95 \mathrm{~kg} / \mathrm{m}^{2}$ for overweight, and $>24.55 \mathrm{~kg} / \mathrm{m}^{2}$ for obese. Similarly, for 15 -year-old girls, the cut-off values are: BMI $<16.18 \mathrm{~kg} / \mathrm{m}^{2}$ for thinness, $>22.49 \mathrm{~kg} / \mathrm{m}^{2}$ for overweight, and $>26.07$ $\mathrm{kg} / \mathrm{m}^{2}$ for obese (Table 3 ).

\section{Comments}

The left-skewed anthropometric indices of the present study population were observed (especially BMI) when the study population was classified according to the criteria by the IOTF (Cole and Lobstein 2012) and by the WHO (World Health Organization 2007). The skewness resulted the majority of the children being incorrectly classified as underweight. Previous studies have also highlighted similar limitations (Chen and Chang 2010; Wickramasinghe et al. 2011). Therefore, to obtain a normal distribution by applying a Box-Cox power transformation, we followed Cole's LMS method (Cole 1990), which was also used to compute smoothed age- and gender-specific centile curves. Waist-to-height ratio and waist circumference are reported to be good screening tools for detecting cardio-metabolic risk factors (Ashwell et al. 2012). Here, two-fifths of the children had $\mathrm{WaC}$ in the 90th percentile. These children can be speculated to represent the obese subpopulation and be potentially vulnerable to multiple non-communicable diseases.

This survey is the first one in Nepal to present age- and gender-specified percentiles for various anthropometric indices, calculated using the LMS method. Furthermore, the proposed Nepali national BMI cut-off values have high discriminating power, sensitivity, and specificity to detect thinness/overweight/obesity based on both gold standards (i.e. the IOTF and WHO cut-offs). The proposed Nepali BMI cut-offs to define thinness, overweight and obesity are distinctly lower compared to the IOTF and WHO reference values. This study also supports the IDF recommended WHtR cut-offs $(>0.50)$ for detecting central obesity for children and adolescents. In conclusion, 
anthropometric references and BMI cut-offs for Nepalese schoolchildren can be applied in future research to compare the status nationally or internationally. However, similar research including other age groups among Nepalese children is recommended.

Access to the dataset: The author(s) may be contacted at University of Oulu.

Source(s) of support: The author(s) received no specific funding for this work.

Disclosure Statement: The authors have no conflict of interest.

\section{References}

Abarca-Gómez L, Abdeen ZA, Hamid ZA, et al. 2017. Worldwide trends in body-mass index, underweight, overweight, and obesity from 1975 to 2016: a pooled analysis of 2416 population-based measurement studies in 128.9 million children, adolescents, and adults. The Lancet. 390(10113):2627-2642.

Aryal KK, Bista B, Khadka BB, Dhimal M, Pandey AR, Mehta R, Poudyal A, et al. 2017. Global school based student health survey Nepal, 2015. Kathamndu, Nepal: Nepal Health Research Council.

Ashwell M, Gunn P, Gibson S. 2012. Waist-to-height ratio is a better screening tool than waist circumference and BMI for adult cardiometabolic risk factors: Systematic review and metaanalysis. Obes Rev. 13(3):275-86.

Bonthuis M, van Stralen KJ, Verrina E, Edefonti A, Molchanova EA, Hokken-Koelega ACS, Schaefer F, Jager KJ. 2012. Use of national and international growth charts for studying height in European children: Development of up-to-date European height-for-age charts. PLoS ONE. 7(8):e42506.

Chen W, Chang M. 2010. New growth charts for Taiwanese children and adolescents based on world health organization standards and health-related physical fitness. Pediatr Neonatol. 51(2):69-79.

Cole TJ. 1990. The LMS method for constructing normalized growth standards. Eur J Clin Nutr. 44(1):45-60.

Cole TJ, Lobstein T. 2012. Extended international (IOTF) body mass index cut-offs for thinness, overweight and obesity. Pediatr Obes. 7(4):284-94. 
de Wilde JA, van Dommelen P, van Buuren S, Middelkoop BJC. 2015. Height of South Asian children in the Netherlands aged 0-20 years: Secular trends and comparisons with current Asian Indian, Dutch and WHO references. Ann Hum Biol. 42(1):38-44.

Ministry of Health. 2017. Nepal demographic and health survey 2016. Kathmandu, Nepal: Ministry of Health, Nepal.

Muzzini E, Aparicio G. 2013. Urban growth and spatial transition in Nepal: An initial assessment. Washington DC: The World Bank.

Natale V, Rajagopalan A. 2014. Worldwide variation in human growth and the World Health Organization growth standards: A systematic review. BMJ Open. 4(1):e003735.

Subedi YP, Marais D, Newlands D. 2017. Where is Nepal in the nutrition transition? Asia Pac J Clin Nutr. 26(2):358-67.

Wickramasinghe VP, Lamabadusuriya SP, Cleghorn GJ, Davies PSW. 2011. Defining anthropometric cut-off levels related to metabolic risk in a group of Sri Lankan children. Ann Hum Biol. 38(5):537-43.

World Health Organization. 1995. Physical status: The use and interpretation of anthropometry. report of a WHO expert committee. Geneva: World Health Organ Tech Rep Ser.

World Health Organization. 2013. Oral health surveys: Basic methods. 5th ed. Geneva: WHO: World Health Organization, WHO.

World Health Organization. 2011. Waist circumference and waist-hip ratio: Report of a WHO expert consultation, Geneva, 8-11 December 2008. Geneva, Switzerland: World Health Organization.

World Health Organization. Growth reference data for 5-19 years [Internet]: World Health Organization; c2007 [accessed 2018 Apr 4,]. Available from: http://www.who.int/growthref/en/ .

Zimmet P, Alberti KGM, Kaufman F, Tajima N, Silink M, Arslanian S, Wong G, et al. 2007. The metabolic syndrome in children and adolescents - an IDF consensus report. Pediatr Diabetes. 8(5):299-306. 
Table 1. Mean (SD), and [95\% Confidence Interval] Anthropometric indices of the study population by age, and gender.

\begin{tabular}{|c|c|c|c|c|c|c|c|c|}
\hline $\begin{array}{l}\text { Age (Years: } \\
\text { Months) }\end{array}$ & Gender & $\mathbf{n}$ & $\begin{array}{c}\text { BMI } \\
\left(\mathrm{kg} / \mathrm{m}^{2}\right)\end{array}$ & $\begin{array}{l}\text { Height } \\
\text { (cm) }\end{array}$ & $\begin{array}{l}\text { Weight } \\
(\mathrm{kg})\end{array}$ & $\begin{array}{l}\text { WaC } \\
(\mathrm{cm})\end{array}$ & WHR & WHtR \\
\hline \multirow[t]{2}{*}{$5: 0-5: 11$} & Boys & 84 & $\begin{array}{c}14.64(1.14) \\
{[14.39,14.88]}\end{array}$ & $\begin{array}{c}106(5.45) \\
{[105.05,107.42]}\end{array}$ & $\begin{array}{c}16.55(2.04) \\
{[16.11,16.99]}\end{array}$ & $\begin{array}{c}51.18(3.51) \\
{[50.42,51.95]}\end{array}$ & $\begin{array}{l}0.94(0.05) \\
{[0.92,0.95]}\end{array}$ & $\begin{array}{l}0.48(0.04) \\
{[0.47,0.49]}\end{array}$ \\
\hline & Girls & 77 & $\begin{array}{c}14.74(2.04) \\
{[14.05,15.44]}\end{array}$ & $\begin{array}{c}105(5.60) \\
{[104.61,107.15]}\end{array}$ & $\begin{array}{c}16.57(3.62) \\
{[15.75,17.39]}\end{array}$ & $\begin{array}{c}49.75(4.34) \\
{[48.77,50.74]}\end{array}$ & $\begin{array}{l}0.89(0.07) \\
{[0.88,0.91]}\end{array}$ & $\begin{array}{l}0.47(0.04) \\
{[0.46,0.48]}\end{array}$ \\
\hline \multicolumn{3}{|c|}{$P$-value ${ }^{a}$} & 0.759 & 0.684 & 0.976 & 0.023 & $<0.001$ & 0.051 \\
\hline \multirow[t]{2}{*}{ 6:0-6:11 } & Boys & 91 & $\begin{array}{c}14.18(1.29) \\
{[13.90,14.45]}\end{array}$ & $\begin{array}{c}109.92(6.56) \\
{[108.55,111.29]}\end{array}$ & $\begin{array}{c}17.15(2.25) \\
{[16.68,17.61]}\end{array}$ & $\begin{array}{c}50.52(4.04) \\
{[49.68,51.36]}\end{array}$ & $\begin{array}{l}0.92(0.05) \\
{[0.91,0.93]}\end{array}$ & $\begin{array}{l}0.46(0.04) \\
{[0.45,0.47]}\end{array}$ \\
\hline & Girls & 86 & $\begin{array}{c}14.25(1.73) \\
{[13.88,14.62]}\end{array}$ & $\begin{array}{c}109.31(5.54) \\
{[108.12,110.50]}\end{array}$ & $\begin{array}{c}17.01(2.16) \\
{[16.55,17.48]}\end{array}$ & $\begin{array}{c}50.68(4.03) \\
{[49.82,51.55]}\end{array}$ & $\begin{array}{l}0.93(0.28) \\
{[0.87,0.99]}\end{array}$ & $\begin{array}{l}0.47(0.03) \\
{[0.46,0.47]}\end{array}$ \\
\hline \multicolumn{3}{|c|}{$P$-value ${ }^{a}$} & 0.756 & 0.507 & 0.689 & 0.793 & 0.828 & 0.569 \\
\hline \multirow[t]{2}{*}{ 12:0-12:11 } & Boys & 213 & $\begin{array}{c}16.11(2.01) \\
{[15.84,16.39]}\end{array}$ & $\begin{array}{c}141.89(8.32) \\
{[140.77,143.01]}\end{array}$ & $\begin{array}{c}32.59(5.62) \\
{[31.83,33.35]}\end{array}$ & $\begin{array}{c}58.74(5.77) \\
{[57.96,59.51]}\end{array}$ & $\begin{array}{l}0.85(0.07) \\
{[0.84,0.86]}\end{array}$ & $\begin{array}{l}0.42(0.04) \\
{[0.41,0.42]}\end{array}$ \\
\hline & Girls & 201 & $\begin{array}{c}16.97(2.89) \\
{[16.57,17.37]}\end{array}$ & $\begin{array}{c}144.20(7.38) \\
{[143.17,145.22]}\end{array}$ & $\begin{array}{c}35.46(7.07) \\
{[34.48,36.45]}\end{array}$ & $\begin{array}{c}59.50(6.73) \\
{[58.56,60.43]}\end{array}$ & $\begin{array}{l}0.80(0.05) \\
{[0.79,0.81]}\end{array}$ & $\begin{array}{l}0.41(0.04) \\
{[0.40,0.42]}\end{array}$ \\
\hline \multicolumn{3}{|c|}{$P$-value ${ }^{a}$} & 0.001 & 0.003 & $<0.001$ & 0.218 & $<0.001$ & 0.594 \\
\hline \multirow[t]{2}{*}{ 15:0-15:11 } & Boys & 208 & $\begin{array}{c}18.21(2.66) \\
{[17.85,18.58]}\end{array}$ & $\begin{array}{c}160.02(8.24) \\
{[158.90,161,15]}\end{array}$ & $\begin{array}{c}46.70(7.66) \\
{[45.65,47.75]}\end{array}$ & $\begin{array}{c}64.60[6.69) \\
{[63.68,65.51]}\end{array}$ & $\begin{array}{l}0.81(0.06) \\
{[0.80,0.82]}\end{array}$ & $\begin{array}{l}0.40(0.04) \\
{[0.40,0.41]}\end{array}$ \\
\hline & Girls & 175 & $\begin{array}{c}19.22(2.35) \\
{[18.87,19.58]}\end{array}$ & $\begin{array}{c}153.63(4.68) \\
{[152.93,154.33]}\end{array}$ & $\begin{array}{c}45.39(6.05) \\
{[44.49,46.30]}\end{array}$ & $\begin{array}{c}65.16(6.93) \\
{[64.12,66.19]}\end{array}$ & $\begin{array}{l}0.78(0.07) \\
{[0.77,0.79]}\end{array}$ & $\begin{array}{l}0.42(0.04) \\
{[0.41,0.43]}\end{array}$ \\
\hline \multicolumn{3}{|c|}{$P$-value ${ }^{a}$} & $<0.001$ & $<0.001$ & 0.067 & 0.421 & $<0.001$ & $<0.001$ \\
\hline
\end{tabular}

Body Mass Index (BMI), Height, Weight, Waist Circumference (WaC), Waist-to-Hip ratio (WHR), and Waist-to-Height-ratio (WHtR)

${ }^{a}$ t-test to compare difference between gender 
Table 2. Age- and gender-specific smoothed body mass index (BMI), Height, Weight, Waist Circumference (WaC), Waist-to-Hip ratio (WHR), and Waist-to-Height-ratio (WHtR) percentiles computed by LMS method.

\begin{tabular}{|c|c|c|c|c|c|c|c|c|c|c|c|c|c|}
\hline \multirow{2}{*}{$\begin{array}{c}\text { Age } \\
\text { (Years: } \\
\text { Months) }\end{array}$} & \multirow[t]{2}{*}{ Percentiles } & BMI & Height & Weight & $\mathbf{W a C}$ & WHR & WHtR & BMI & Height & Weight & $\mathbf{W a C}$ & WHR & WHtR \\
\hline & & \multicolumn{6}{|c|}{ Boys } & \multicolumn{6}{|c|}{ Girls } \\
\hline \multirow[t]{7}{*}{$5: 0-5: 11$} & 3rd & 12.43 & 95.29 & 12.47 & 43.26 & 0.83 & 0.40 & 12.27 & 92.07 & 12.30 & 41.55 & 0.54 & 0.39 \\
\hline & 10th & 12.91 & 98.39 & 13.54 & 45.73 & 0.87 & 0.43 & 12.78 & 96.33 & 13.03 & 44.20 & 0.66 & 0.42 \\
\hline & 25th & 13.48 & 101.77 & 14.71 & 48.19 & 0.90 & 0.46 & 13.39 & 100.59 & 13.94 & 46.89 & 0.79 & 0.44 \\
\hline & 50th & 14.12 & 105.45 & 15.99 & 50.64 & 0.94 & 0.48 & 14.11 & 104.86 & 15.09 & 49.60 & 0.91 & 0.47 \\
\hline & 75th & 14.89 & 109.49 & 17.40 & 53.07 & 0.97 & 0.50 & 15.01 & 109.12 & 16.62 & 52.36 & 1.03 & 0.50 \\
\hline & 90th & 15.82 & 113.96 & 18.94 & 55.49 & 1.00 & 0.54 & 16.18 & 113.38 & 18.80 & 55.14 & 1.16 & 0.52 \\
\hline & 97th & 17.00 & 118.91 & 20.65 & 57.90 & 1.04 & 0.56 & 17.77 & 117.65 & 22.32 & 57.94 & 1.29 & 0.55 \\
\hline \multirow[t]{7}{*}{ 6:0-6:11 } & 3rd & 12.14 & 99.02 & 13.39 & 43.40 & 0.81 & 0.39 & 12.21 & 97.72 & 13.09 & 42.41 & 0.55 & 0.38 \\
\hline & 10th & 12.71 & 102.50 & 14.61 & 45.97 & 0.84 & 0.42 & 12.75 & 102.03 & 14.67 & 45.12 & 0.67 & 0.40 \\
\hline & 25th & 13.39 & 106.22 & 15.95 & 48.56 & 0.89 & 0.44 & 13.39 & 106.35 & 16.31 & 47.89 & 0.78 & 0.44 \\
\hline & 50th & 14.21 & 110.21 & 17.42 & 51.18 & 0.93 & 0.47 & 14.17 & 110.66 & 17.99 & 50.74 & 0.90 & 0.46 \\
\hline & 75th & 15.25 & 114.50 & 19.05 & 53.83 & 0.96 & 0.50 & 15.13 & 114.97 & 19.75 & 53.65 & 1.00 & 0.49 \\
\hline & 90th & 16.61 & 119.12 & 20.84 & 56.50 & 0.99 & 0.52 & 16.36 & 119.28 & 21.54 & 56.62 & 1.13 & 0.51 \\
\hline & 97th & 18.53 & 124.10 & 22.82 & 59.19 & 1.04 & 0.55 & 18.05 & 123.60 & 23.39 & 59.66 & 1.25 & 0.54 \\
\hline \multirow{7}{*}{$\begin{array}{l}\text { 12:0- } \\
12: 11\end{array}$} & 3rd & 13.29 & 124.43 & 23.22 & 49.00 & 0.73 & 0.35 & 13.41 & 131.24 & 24.30 & 48.36 & 0.62 & 0.34 \\
\hline & 10th & 14.19 & 130.95 & 26.07 & 51.77 & 0.77 & 0.37 & 14.29 & 135.38 & 27.59 & 51.51 & 0.69 & 0.37 \\
\hline & 25th & 15.27 & 136.93 & 29.24 & 54.84 & 0.80 & 0.39 & 15.32 & 139.52 & 31.28 & 55.02 & 0.76 & 0.40 \\
\hline & 50th & 16.60 & 142.47 & 32.77 & 58.29 & 0.85 & 0.42 & 16.54 & 143.66 & 35.45 & 58.98 & 0.82 & 0.43 \\
\hline & 75th & 18.28 & 147.64 & 36.68 & 62.17 & 0.90 & 0.44 & 18.01 & 147.79 & 40.14 & 63.42 & 0.89 & 0.46 \\
\hline & 90th & 20.49 & 152.51 & 41.03 & 66.58 & 0.94 & 0.47 & 19.85 & 151.93 & 45.42 & 68.47 & 0.95 & 0.49 \\
\hline & 97th & 23.57 & 157.10 & 45.85 & 71.63 & 0.98 & 0.51 & 22.17 & 156.07 & 51.35 & 74.25 & 1.02 & 0.52 \\
\hline \multirow{7}{*}{$\begin{array}{l}\text { 15:0- } \\
15: 11\end{array}$} & 3rd & 14.89 & 141.14 & 32.00 & 53.81 & 0.68 & 0.34 & 14.73 & 142.99 & 33.99 & 53.42 & 0.65 & 0.32 \\
\hline & 10th & 16.12 & 148.72 & 35.98 & 56.59 & 0.73 & 0.36 & 15.92 & 146.64 & 37.00 & 56.53 & 0.70 & 0.35 \\
\hline & 25th & 17.47 & 155.10 & 40.34 & 59.81 & 0.77 & 0.38 & 17.29 & 150.30 & 40.38 & 60.10 & 0.74 & 0.39 \\
\hline & 50th & 18.94 & 160.63 & 45.15 & 63.60 & 0.81 & 0.40 & 18.88 & 153.95 & 44.17 & 64.25 & 0.78 & 0.41 \\
\hline & 75th & 20.55 & 165.54 & 50.43 & 68.13 & 0.86 & 0.43 & 20.75 & 157.60 & 48.46 & 69.14 & 0.83 & 0.44 \\
\hline & 90th & 22.31 & 169.97 & 56.23 & 73.70 & 0.90 & 0.47 & 22.96 & 161.26 & 53.30 & 74.99 & 0.87 & 0.47 \\
\hline & 97th & 24.25 & 174.00 & 62.58 & 80.74 & 0.95 & 0.51 & 25.62 & 164.91 & 58.82 & 82.16 & 0.91 & 0.50 \\
\hline
\end{tabular}


Table 3. Proposed BMI cut-offs values for underweight, overweight, and obesity with corresponding Z-score and percentile by age and gender.

\begin{tabular}{|c|c|c|c|c|}
\hline \multirow[t]{2}{*}{ Age (Years:Months) } & \multirow[t]{2}{*}{ Gender } & \multicolumn{3}{|c|}{ BMI cut-offs $\left(\mathrm{kg} / \mathrm{m}^{2}\right)$} \\
\hline & & $\begin{array}{l}\text { Thinness } \\
\left(-1.2 \mathrm{SD} / 12^{\text {th }}\right. \\
\text { percentile) }\end{array}$ & $\begin{array}{c}\text { Overweight } \\
\left(+1.2 \mathrm{SD} / \mathbf{8 8}^{\text {th }}\right. \\
\text { percentile })\end{array}$ & $\begin{array}{c}\text { Obesity } \\
\left(+2.1 \mathrm{SD} / 98^{\text {th }}\right. \\
\text { percentile })^{-}\end{array}$ \\
\hline \multirow[t]{2}{*}{ 5:0-5:11 } & Boys & 13.02 & 15.63 & 17.21 \\
\hline & Girls & 12.90 & 15.92 & 18.07 \\
\hline \multirow[t]{2}{*}{ 6:0-6:11 } & Boys & 12.84 & 16.31 & 18.89 \\
\hline & Girls & 12.88 & 16.09 & 18.37 \\
\hline \multirow[t]{2}{*}{ 12:0-12:11 } & Boys & 14.40 & 20.00 & 24.15 \\
\hline & Girls & 14.49 & 19.45 & 22.58 \\
\hline \multirow[t]{2}{*}{ 15:0-15:11 } & Boys & 16.39 & 21.95 & 24.55 \\
\hline & Girls & 16.18 & 22.49 & 26.07 \\
\hline
\end{tabular}



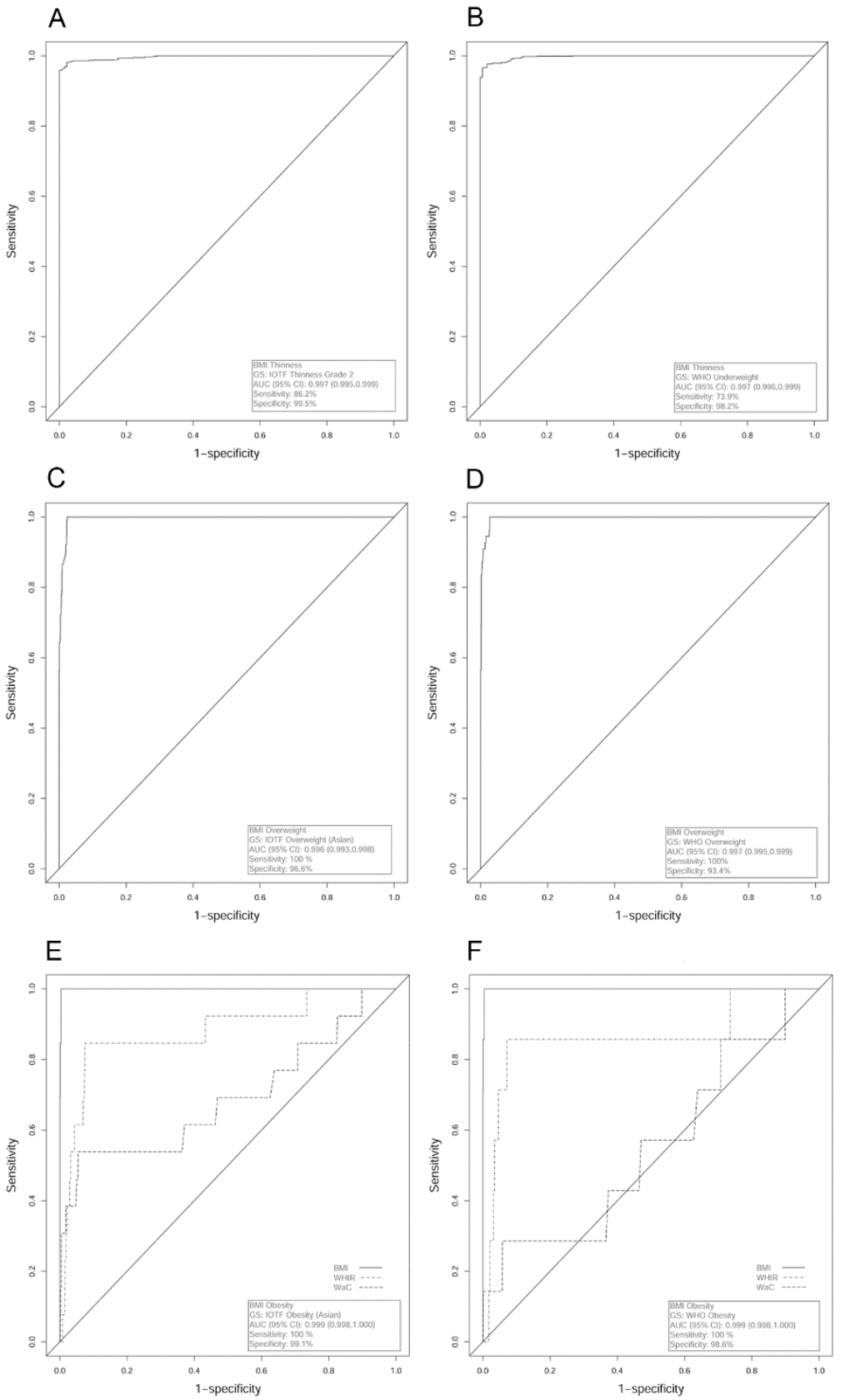